\title{
Partisipasi Masyarakat Berdasarkan Motivasi dalam Meningkatkan Cakupan D/S Posyandu di Wilayah Puskesmas Rambipuji, Kaliwates dan Arjasa Kabupaten Jember
}

\author{
Jamhariyah \\ Akademi Kebidanan Jember, Indonesia \\ e-mail: jamhariyah64@gmail.com
}

\begin{abstract}
This research is motivated by the low participation of posyandu visits with D/S indicators below the SPM target in 2016 in the Arjasa, Kaliwates and Rambipuji District Health Centers Jember. The theoretical approach used in this study is the theory of motivation from Herzberg. The purpose of this study is to develop a model of community participation based on motivation in increasing the scope of D/S posyandu. Correlational research design with cross sectional approach. The population in this study is the Village Head, Community Figure, PKK and Cadres mobilization team as many as 220 people. Large sample for village heads, Community Leaders, PKK Activator with a total sample of 56 people, while for cadres obtained with a sample of 90 people using simple randome sampling. The instrument uses a questionnaire. The analysis technique used is the exact fishers test with the help of the SPSS program. The conclusion of the research shows that there is a relationship between intrinsic motivation and extrinsic motivation in the village head of the PKK driving team, community leaders and posyandu cadres with the D/S Coverage in the Arjasa Community Health Center, Kaliwates and Rambipuji, Jember Regency. The solution that can be done from the results of the study, midwives need to do socialization of the village chief's duties, community leaders, PKK and Cadre driving teams in posyandu activities, and provide motivation with intrinsic and extrinsic motivation models, which are equipped with learning modules.
\end{abstract}

Keywords: cakupan D/S, model partisipasi, motivasi.

\section{Pendahuluan}

Salah satu wujud pemberdayaan masyarakat di bidang kesehatan adalah tumbuh dan berkembangnya Posyandu. Posyandu adalah salah satu bentuk Upaya Kesehatan Bersumberdaya Masyarakat (UKBM) yang dikelola dan diselenggarakan dari, oleh, untuk dan bersama masyarakat dalam penyelenggaraan pembangunan kesehatan, guna memberdayakan masyarakat dalam memperoleh pelayanan kesehatan dasar untuk mempercepat penurunan angka kematian ibu dan bayi (Depkes RI, 2006). Posyandu merupakan salah satu pelayanan kesehatan di desa untuk memudahkan masyarakat untuk mengetahui atau memeriksakan kesehatan terutama untuk ibu hamil dan anak balita. Keaktifan keluarga pada setiap kegiatan posyandu tentu akan berpengaruh pada keadaan status gizi anak balitanya, karena salah satunya tujuan posyandu adalah memantau peningkatan status gizi masyarakat terutama anak balita dan ibu hamil (Adisasmito, 2007).

Keberhasilan Posyandu berdasarkan pada peran serta masyarakat dengan indikator yaitu: D/S (D adalah balita yang ditimbang, sedangkan $\mathrm{S}$ adalah semua balita yang ada di wilayah kerja Posyandu). Selain itu, keberhasilan posyandu ditentukan juga oleh keberhasilan program Posyandu. Indikator dari keberhasilan program Posyandu salah satunya adalah N/D ( $\mathrm{N}$ adalah balita yang naik berat badannya, sedangkan $\mathrm{D}$ adalah balita yang ditimbang).

Di Kabupaten Jember terdapat Posyandu sebanyak 2.830 buah yang terdiri dari Posyandu Pratama 0,24 \%, Posyandu Madya 7,11\%, Posyandu Purnama 80,24\% dan Posyandu Mandiri sebanyak 12,40\%. Jumlah Kader kesehatan Posyandu di Kabupaten Jember adalah sebanyak 14.150 orang, sedangkan Kader Kesehatan Posyandu yang aktif adalah 9.450 orang (Dinkes Jember, 2015).

Persentase cakupan penimbangan balita di Posyandu wilayah Puskesmas Kabupaten Jember tahun 2015-2016, terdapat 3 (tiga) Kecamatan dengan cakupan D/S yaitu Kecamatan Arjasa (68,86\%), Kecamatan Kaliwates( 70,85\%), Kecamatan Rambipuji ( $60,23 \%$ ). Ketiga kecamatan tersebut selain cakupan $\mathrm{D} / \mathrm{S}$ rendah juga dari waktu ke waktu mengalami trend yang tetap bahkan di Kecamatan Kaliwates mengalami trend penurunan. Data yang diperoleh dalam tiga tahun terakhir, jumlah Balita 187.081 dan balita yang ditimbang 149.782, jumlah balita 
198.938, dan balita ditimbang 149.441 serta jumlah balita 196.518 , balita yang ditimbang 155.064. Data terakhir dengan persentase $78,91 \%$, yang berarti masih belum mencapai target yaitu $85 \%$. Hal menggambarkan tingkat partisipasi masyarakat berkunjung ke fasilitas kesehatan atau ke posyandu masih rendah. Salah satu faktor yang mempengaruhi rendahnya cakupan $\mathrm{D} / \mathrm{S}$ adalah rendahnya partisipasi masyarakat terhadap posyandu.

\section{Metode}

\subsection{Metode Pengumpulan Data}

Desain yang digunakan dalam penelitian ini adalah corelational dengan pendekatan Cross Sectional. Teknik pengambilan sampling penelitian ini menggunakan Simple Random Sampling yaitu sebanyak 144 responden yang terbagi di Wilayah Puskesmas Rambipuji, Puskesmas Kaliwates dan Puskesmas Arjasa. Waktu penelitian dilakukan pada bulan Juli Nopember 2017. Pengumpulan data menggunakan non tes.

\subsection{Metode Analisis Data}

Analisis data yaitu univariat dan bivariat menggunakan Uji Fisher's exact.

\section{Hasil dan Pembahasan}

Berikut Analisa Univariat yang didapatkan dari pengisian kuisioner pada penelitian disajikan pada Tabel 1.

Tabel 1. Motivasi intrinsik kepala desa pada kegiatan Posyandu

\begin{tabular}{clcc}
\hline No & $\begin{array}{l}\text { Motivasi } \\
\text { Intrinsik }\end{array}$ & Jumlah & $\%$ \\
\hline 1 & Tinggi & 10 & 56,00 \\
2 & Rendah & 8 & 44,00 \\
& Total & 18 & 100,00 \\
\hline
\end{tabular}

Dari tabel 1 dapat dilihat tinggi motivasi instrinsik kepala desa sebanyak 10 orang $(56 \%)$, dan rendah motivasi instrinsik sebanyak 8 orang $(44 \%)$

Tabel 2. Motivasi ekstrinsik kepala desa pada kegiatan Posyandu

\begin{tabular}{clcc}
\hline No & $\begin{array}{l}\text { Motivasi } \\
\text { Intrinsik }\end{array}$ & Jumlah & \% \\
\hline 1 & Tinggi & 7 & 39,00 \\
2 & Rendah & 11 & 61,00 \\
& Total & 18 & 100,00 \\
\hline
\end{tabular}

Dari tabel dapat dilihat tinggi motivasi ekstrinsik kepala desa sebanyak 7 orang $(39 \%)$, dan rendah motivasi ekstriksi sebanyak 11 orang $(61 \%)$

Tabel 3. Motivasi intrinsik tokoh masyarakat pada kegiatan Posyandu

\begin{tabular}{clcc}
\hline No & $\begin{array}{l}\text { Motivasi } \\
\text { Intrinsik }\end{array}$ & Jumlah & \% \\
\hline 1 & Tinggi & 7 & 39,00 \\
2 & Rendah & 11 & 61,00 \\
& Total & 18 & 100,00 \\
\hline
\end{tabular}

Dari tabel 3. dapat dilihat tinggi motivasi instrinsik tokoh masyarakat sebanyak 7 orang (39\%), dan rendah motivasi instriksi sebanyak 11 orang $(61 \%)$

Tabel 4. Motivasi ektrinsik tokoh masyarakat pada kegiatan Posyandu

\begin{tabular}{clcc}
\hline No & $\begin{array}{l}\text { Motivasi } \\
\text { ekstrinsik }\end{array}$ & Jumlah & $\%$ \\
\hline 1 & Tinggi & 8 & 44,00 \\
2 & Rendah & 10 & 56,00 \\
& Total & 18 & 100,00 \\
\hline
\end{tabular}

Dari tabel 4. dapat dilihat tinggi motivasi ekstrinsik tokoh masyarakat sebanyak 8 orang (44\%), dan rendah motivasi ekstriksi sebanyak 10 orang $(56 \%)$.

Tabel 5. Motivasi intrinsik penggerak PKK pada kegiatan Posyandu

\begin{tabular}{clcc}
\hline No & $\begin{array}{l}\text { Motivasi } \\
\text { Intrinsik }\end{array}$ & Jumlah & $\%$ \\
\hline 1 & Tinggi & 10 & 56,00 \\
2 & Rendah & 8 & 44,00 \\
& Total & 18 & 100,00 \\
\hline
\end{tabular}

Dari tabel 5. dapat dilihat tinggi motivasi instrinsik penggerak PKK sebanyak 10 orang (56\%), dan rendah motivasi ekstriksi sebanyak 8 orang $(44 \%)$.

Tabel 6. Motivasi ektrinsik penggerak PKK pada kegiatan posyandu

\begin{tabular}{clcc}
\hline No & $\begin{array}{l}\text { Motivasi } \\
\text { Intrinsik }\end{array}$ & Jumlah & $\mathbf{\%}$ \\
\hline 1 & Tinggi & 9 & 50,00 \\
2 & Rendah & 9 & 50,00 \\
& Total & 18 & 100,00 \\
\hline
\end{tabular}


Dari tabel 6. dapat dilihat tinggi motivasi ekstrinsik penggerak PKK sebanyak 9 orang (50\%), dan rendah motivasi ekstriksi sebanyak 9 orang $(50 \%)$.

Tabel 7. Motivasi intrinsik kader posyandu pada kegiatan posyandu

\begin{tabular}{clcc}
\hline No & $\begin{array}{c}\text { Motivasi } \\
\text { Intrinsik }\end{array}$ & Jumlah & $\mathbf{\%}$ \\
\hline 1 & Tinggi & 40 & 44,00 \\
2 & Rendah & 50 & 56,00 \\
& Total & 90 & 100,00 \\
\hline
\end{tabular}

Dari tabel 7. dapat dilihat tinggi motivasi instrinsik kader posyandu sebanyak 40 orang (44\%), dan rendah motivasi ekstriksi sebanyak 50 orang $(56 \%)$.

Tabel 8. Motivasi ektrinsik kader posyandu pada kegiatan posyandu

\begin{tabular}{clcc}
\hline No & $\begin{array}{l}\text { Motivasi } \\
\text { ekstrinsik }\end{array}$ & Jumlah & $\mathbf{\%}$ \\
\hline 1 & Tinggi & 43 & 48,00 \\
2 & Rendah & 47 & 52,00 \\
& Total & 90 & 100,00 \\
\hline
\end{tabular}

Dari tabel 8. dapat dilihat tinggi motivasi ekstrinsik kader posyandu sebanyak 43 orang (48\%), dan rendah motivasi ekstriksi sebanyak 47 orang $(52 \%)$.

Tabel 9. Cakupan D/S Desa wilayah Puskesmas Rambipuji, Kaliwates dan Arjasa Kab. Jember Tahun 2017

\begin{tabular}{|c|c|c|c|c|c|}
\hline \multirow[t]{3}{*}{ No } & \multirow{3}{*}{ Kecamatan } & \multicolumn{4}{|c|}{ Cakupan D/S } \\
\hline & & \multicolumn{2}{|c|}{ Baik } & \multicolumn{2}{|c|}{$\begin{array}{c}\text { Tidak } \\
\text { baik }\end{array}$} \\
\hline & & $\sum$ & $\%$ & $\sum$ & $\%$ \\
\hline 1 & Rambi & 2 & 33,00 & 4 & 67,00 \\
\hline 2 & Kaliwates & 2 & 33,00 & 4 & 67,00 \\
\hline 3 & Arjasa & 4 & 67,00 & 2 & 33,00 \\
\hline
\end{tabular}

Dari tabel 9. dapat dilihat paling tinggi cakupan D/S adalah kec arjasa sebanyak 4 (33\%), dan rendahnya cakupan $\mathrm{D} / \mathrm{s}$ adalah kec. Rambi dan kaliwates sebanyak 2 (33\%).
Berikut Analisa bivariat yang didapatkan dari pengisian kuisioner pada penelitian adalah sebagai berikut:

Tabel 10. Hubungan motivasi intrinsik kepala desa pada kegiatan posyandu dengan cakupan $\mathrm{D} / \mathrm{S}$ di posyandu

\begin{tabular}{|c|c|c|c|c|}
\hline \multirow{2}{*}{$\begin{array}{l}\text { Motivasi } \\
\text { Intrinsik }\end{array}$} & \multicolumn{3}{|c|}{ Cakupan D/S } & \multirow{3}{*}{$\begin{array}{l}p \text { - } \\
\text { value }\end{array}$} \\
\hline & $\begin{array}{c}\text { Tidak } \\
\text { baik }\end{array}$ & Baik & Jumlah & \\
\hline & $\mathrm{N}$ & $\mathrm{n}$ & $\mathrm{n}$ & \\
\hline Rendah & 8 & 0 & 10 & 0.001 \\
\hline Tinggi & 2 & 8 & 8 & \\
\hline Total & 10 & 8 & 18 & \\
\hline
\end{tabular}

Dari tabel 10. Hasil analisis hubungan Motivasi instrinsik kepala desa dengan cakupan $\mathrm{D} / \mathrm{S}$ mempunyai nilai $\mathrm{p}$ value 0.001 .

Tabel 11. Hubungan motivasi ekstrinsik kepala desa pada kegiatan posyandu dengan cakupan $\mathrm{D} / \mathrm{S}$

\begin{tabular}{|c|c|c|c|c|}
\hline \multirow{3}{*}{$\begin{array}{l}\text { Motivasi } \\
\text { Intrinsik }\end{array}$} & \multicolumn{2}{|c|}{ Cakupan D/S } & \multirow[b]{2}{*}{ Jumlah } & \multirow{3}{*}{$\begin{array}{l}p \text { - } \\
\text { value }\end{array}$} \\
\hline & $\begin{array}{c}\text { Tidak } \\
\text { baik }\end{array}$ & Baik & & \\
\hline & $\mathbf{N}$ & $\mathbf{n}$ & $\mathbf{n}$ & \\
\hline Rendah & 9 & 2 & 11 & 0.013 \\
\hline Tinggi & 1 & 6 & 7 & \\
\hline Total & 10 & 8 & 18 & \\
\hline
\end{tabular}

Dari tabel 11. Hasil analisis hubungan Motivasi ekstrinsik kepala desa dengan cakupan $\mathrm{D} / \mathrm{S}$ mempunyai nilai $\mathrm{p}$ value 0.013 .

Tabel 12. Hubungan motivasi intrinsik tokoh masyarakat pada kegiatan posyandu dengan cakupan D/S

\begin{tabular}{lcccc}
\hline Motivasi & \multicolumn{3}{c}{ Cakupan D/S } & p- \\
\cline { 2 - 4 } Intrinsik & $\begin{array}{c}\text { Tidak } \\
\text { baik }\end{array}$ & Baik & Jumlah & value \\
\cline { 2 - 4 } & $\mathbf{N}$ & $\mathbf{n}$ & $\mathbf{n}$ & \\
\cline { 2 - 4 } Rendah & 10 & 1 & 11 & 0.000 \\
Tinggi & 0 & 7 & 7 & \\
Total & 10 & 8 & 18 & \\
\hline
\end{tabular}

Dari tabel 12. Hasil analisis hubungan Motivasi instrinsik tokoh masyarakat dengan cakupan $\mathrm{D} / \mathrm{S}$ mempunyai nilai $\mathrm{p}$ value 0.000 . 
Tabel 13. Hubungan motivasi ekstrinsik tokoh masyarakat pada kegiatan posyandu dengan cakupan D/S

\begin{tabular}{lcccc}
\hline Motivasi & \multicolumn{3}{c}{ Cakupan D/S } & p- \\
\cline { 2 - 4 } Intrinsik & $\begin{array}{l}\text { Tidak } \\
\text { baik }\end{array}$ & Baik & Jumlah & value \\
\cline { 2 - 4 } & $\mathrm{N}$ & $\mathrm{n}$ & $\mathrm{n}$ & \\
\cline { 2 - 4 } Rendah & 9 & 1 & 10 & 0.003 \\
Tinggi & 1 & 7 & 8 & \\
Total & 10 & 8 & 18 & \\
\hline
\end{tabular}

Dari tabel 13. Hasil analisis Hubungan Motivasi ekstrinsik tokoh masyarakat dengan cakupan D/S mempunyai nilai $\mathrm{p}$ value 0.003 .

Tabel 14. Hubungan motivasi intrinsik penggerak PKK pada kegiatan posyandu dengan cakupan $\mathrm{D} / \mathrm{S}$

\begin{tabular}{lcccc}
\hline Motivasi & \multicolumn{3}{c}{ Cakupan D/S } & p- \\
\cline { 2 - 4 } Intrinsik & $\begin{array}{c}\text { Tidak } \\
\text { baik }\end{array}$ & Baik & Jumlah & value \\
\cline { 2 - 4 } & $\mathrm{N}$ & $\mathrm{n}$ & $\mathrm{n}$ & \\
\cline { 2 - 4 } Rendah & 7 & 1 & 8 & 0.025 \\
Tinggi & 3 & 7 & 10 & \\
Total & 10 & 8 & 18 & \\
\hline
\end{tabular}

Dari tabel 14. Hasil analisis hubungan Motivasi instrinsik penggerak PKK dengan cakupan $\mathrm{D} / \mathrm{S}$ mempunyai nilai $\mathrm{p}$ value 0.003 .

Tabel 15. Hubungan motivasi ekstrinsik penggerak PKK pada kegiatan posyandu dengan cakupan $\mathrm{D} / \mathrm{S}$

\begin{tabular}{lcccc}
\hline Motivasi & \multicolumn{3}{c}{ Cakupan D/S } & p- \\
\cline { 2 - 4 } Intrinsik & $\begin{array}{c}\text { Tidak } \\
\text { baik }\end{array}$ & Baik & Jumlah & value \\
\cline { 2 - 4 } & $\mathrm{N}$ & $\mathrm{n}$ & $\mathrm{n}$ & \\
\cline { 2 - 4 } Rendah & 8 & 1 & 9 & 0.015 \\
Tinggi & 2 & 7 & 9 & \\
Total & 10 & 8 & 18 & \\
\hline
\end{tabular}

Dari tabel 15. Hasil analisis hubungan Motivasi ekstrinsik penggerak PKK dengan cakupan D/S mempunyai nilai $\mathrm{p}$ value 0.015 .
Tabel 16. Hubungan motivasi intrinsik kader posyandu pada kegiatan posyandu dengan cakupan D/S

\begin{tabular}{lcccc}
\hline Motivasi & \multicolumn{3}{c}{ Cakupan D/S } & p- \\
\cline { 2 - 4 } Intrinsik & $\begin{array}{c}\text { Tidak } \\
\text { baik }\end{array}$ & Baik & Jumlah & value \\
\cline { 2 - 4 } & $\mathbf{N}$ & $\mathbf{n}$ & $\mathbf{n}$ & \\
\cline { 2 - 4 } Rendah & 33 & 17 & 50 & 0.033 \\
Tinggi & 17 & 23 & 40 & \\
Total & 50 & 40 & 18 & \\
\hline
\end{tabular}

Dari tabel 16. Hasil analisis hubungan Motivasi instrinsik kader posyandu dengan cakupan D/S mempunyai nilai $\mathrm{p}$ value 0.033 .

Tabel 17. Hubungan motivasi ekstrinsik kader posyandu pada kegiatan posyandu dengan cakupan $\mathrm{D} / \mathrm{S}$

\begin{tabular}{lcccc}
\hline Motivasi & \multicolumn{3}{c}{ Cakupan D/S } & p- \\
\cline { 2 - 4 } Intrinsik & $\begin{array}{l}\text { Tidak } \\
\text { baik }\end{array}$ & Baik & Jumlah & value \\
\cline { 2 - 4 } & $\mathbf{N}$ & $\mathbf{n}$ & $\mathbf{n}$ & \\
\cline { 2 - 4 } Rendah & 32 & 15 & 50 & 0.019 \\
Tinggi & 18 & 25 & 40 & \\
Total & 50 & 40 & 18 & \\
\hline
\end{tabular}

Dari tabel 17. Hasil analisis hubungan Motivasi ekstrinsik kader posyandu dengan cakupan $\mathrm{D} / \mathrm{S}$ mempunyai nilai $\mathrm{p}$ value 0.019 .

Analisa motivasi intrinsik dan ekstrinsik kepala desa pada kegiatan posyandu dengan cakupan $\mathrm{D} / \mathrm{S} \quad \mathrm{di}$ posyandu wilayah Puskesmas Rambipuji, Kaliwates dan Arjasa Kab. Jember.

Hasil analisa motivasi intrinsik kepala desa pada kegiatan posyandu dengan cakupan $\mathrm{D} / \mathrm{S}$ di posyandu dengan menggunakan uji fisher's exact diperoleh hasil value yaitu 0.001 hasil ini lebih kecil dari 0.05 artinya motivasi intrinsik berhubungan dengan cakupan $\mathrm{D} / \mathrm{S}$ dengan keterikatan sebesar 0,004.Analisa motivasi ekstrinsik kepala desa pada kegiatan posyandu dengan cakupan $\mathrm{D} / \mathrm{S}$ di posyandu dengan menggunakan uji dengan fisher's exact diperoleh hasil value yaitu 0.013 hasil ini lebih kecil dari 0.05 artinya motivasi ekstrinsik berhubungan dengan cakupan $\mathrm{D} / \mathrm{S}$ dengan keterikatan sebesar 0,020 .

3.1 Analisa motivasi intrinsik dan ekstrinsik tokoh masyarakat pada kegiatan posyandu dengan cakupan $\mathrm{D} / \mathrm{S}$ 
Hasil analisa motivasi intrinsik tokoh masyarakat pada kegiatan posyandu dengan cakupan $\mathrm{D} / \mathrm{S}$ di posyandu dengan menggunakan uji dengan fisher's exact diperoleh hasil value yaitu 0.000 hasil ini lebih kecil dari 0.05 artinya motivasi intrinsik berhubungan dengan cakupan $\mathrm{D} / \mathrm{S}$ dengan keterikatan sebesar 0,001.Hasil analisa motivasi ekstrinsik tokoh masyarakat pada kegiatan posyandu dengan cakupan $\mathrm{D} / \mathrm{S}$ di posyandu dengan menggunakan uji dengan Fisher's exact diperoleh hasil value yaitu 0.003 hasil ini lebih kecil dari 0,05

3.2 Analisa motivasi intrinsik dan ekstrinsik Penggerak PKK pada kegiatan posyandu dengan cakupan $\mathrm{D} / \mathrm{S}$ di posyandu wilayah Puskesmas Rambipuji, Kaliwates dan Arjasa Kab. Jember.

Hasil analisa motivasi intrinsik Penggerak PKK pada kegiatan posyandu dengan cakupan $\mathrm{D} / \mathrm{S}$ di posyandu dengan menggunakan di uji dengan Fisher's exact diperoleh hasil value yaitu 0.025 hasil ini lebih kecil dari 0.05 . hal ini berarti ada hubungan antar motivasi intrinsik dan penggerak PKK.Hasil analisa motivasi ekstrinsik penggerak PKK pada kegiatan posyandu dengan cakupan $\mathrm{D} / \mathrm{S}$ di posyandu dengan menggunakan uji dengan Fisher's exact diperoleh hasil value yaitu 0.015 hasil ini lebih kecil dari 0.05 .

3.3 Analisa motivasi intrinsik dan ekstrinsik kader posyandu pada kegiatan posyandu dengan cakupan $\mathrm{D} / \mathrm{S}$ di posyandu wilayah Puskesmas Rambipuji, Kaliwates dan Arjasa Kab. Jember.

Hasil analisa motivasi intrinsik kader posyandu pada kegiatan posyandu dengan cakupan $\mathrm{D} / \mathrm{S}$ di posyandu dengan menggunakan uji dengan Fisher's exact diperoleh hasil value yaitu 0.033 hasil ini lebih kecil dari 0.05 . hal ini berarti ada hubungan anatar motivasi intrinsik dan kader posyandu. Hasil analisa motivasi ekstrinsik kader posyandu pada kegiatan posyandu dengan cakupan $\mathrm{D} / \mathrm{S}$ di posyandu dengan menggunakan uji dengan Fisher's exact diperoleh hasil value yaitu 0.019 hasil ini lebih kecil dari 0.05 .

3.4 Model partisipasi masyarakat berdasarkan motivasi dalam meningkatkan cakupan D/S posyandu di Wilayah Puskesmas
Arjasa, Puskesmas Kaliwates dan Puskesmas Rambipuji Kabupaten Jember Berdasarkan hasil uji statistik, pengaruh yang paling besar adalah motivasi intrinsik dan ekstrinsik tokoh masyarakat (intrinsik p-value 0.000 dan ekstrinsik $p$-value 0.003). Tokoh masyarakat sebagai panutan memiliki peran yang besar untuk mengubah perilaku masyarakat terhadap kehadiran mengikuti posyandu. Akan tetapi berdasarkan penelitian ini, tokoh masyarakat memiliki motivasi intrinsik dan ekstrinsik yang rendah. Sebagaimana data pada tabel cakupan D/S tabel 4.12 menunjukkan 10 atau $56,00 \%$ desa berada pada cakupan $\mathrm{D} / \mathrm{S}$ yang tidak baik.

Upaya dalam meningkatkan partisipasi masyarakat berdasarkan motivasi dapat dilakukan dengan memberikan pemahaman bahwa kegiatan posyandu juga menjadi tanggung jawab dari kepala desa.

\section{Simpulan dan Saran \\ 4.1 Simpulan}

Pengaruh paling besar dalam meningkatkan cakupan $\mathrm{D} / \mathrm{S}$ di posyandu Wilayah Puskesmas Rambipuji, Kaliwates dan Arjasa Kab. Jember tahun 2017 adalah motivasi intrinsik dan ekstrinsik tokoh masyarakat

\subsection{Saran}

Peningkatan Partisipasi kunjungan Posyandu dapat dilakukan dengan memotivasi intrinsik dan motivasi ekstrinsik pada kepala desa, penggerak PKKK, Tokoh masyarakat dan Kader di wilayah Puskesmas Kaliwates, Arjasa dan Rambipuji Kabupaten Jember.

\section{Daftar Pustaka}

Arikunto, Suharsimi. (2002). Prosedur Penelitian. Jakarta: Rineka Cipta

Adisasmito, W. 2007. Sistem Kesehatan. Jakarta. PT. Raja Grafindo Persada

Agenda, Erliana Ginting (2009). Pengaruh Motivasi Kerja Petugas KIA Terhadap Mutu Pelayanan KIA Di Puskesms Kbupaten Aceh Tenggara. Tesis, Universitas Sumatra Utara, Medan. 
Burke, Edmund M., (2004). Sebuah Pendekatan Partisipatif dalam Perencanaan Kota (Terjemahan A Participatory Approach to Urban Planning). Bandung: Penerbit Yayasan Sugijanto Soegijoko.

Depkes RI. (2006). Buku Pedoman Petugas Lapangan. Jakarta: Komite Nasional Posyandu.

Dinas Kesehatan Kabupaten Jember. (2015). Profil Kesehatan Kabupaten Jember.

Depkes RI. Pedoman Umum Pengelolaan Posyandu.Jakarta. (2006)

Dinkes Provinsi Jawa Timur. (2005) Buku Pegangan Kader Posyandu .Subdin. PSD, Surabaya

Deasy, Haruna. A. (2014). Partisipasi Masyarakat Dalam Layanan Posyandu Berbasis Masyarakat terhadap Pertumbuhan Balita ( Di Desa Mergowati Kecamatan Kedu Kabupaten Temanggung. Skripsi Jurusan Pendidikan Guru Pendidikan Anak Usia Dini Fakultas Ilmu Pendidikan Unesa.

Hamzah B, Uno. (2006). Teori Motivasi \& Pengukurannya, Jakarta : PT Bumi Aksara

Hasibuan, M. (2004). Organisasi dan Motivasi: Dasar Peningkatan Produktivitas . Jakarta: Bumi Aksara.

Notoatmodjo, S. (2007). Kesehatan Masyarakat Ilmu dan Seni. Renika Cipta. Jakarta.

Notoatmodjo, S. (2010). Ilmu Perilaku Kesehatan . Renika Cipta. Jakarta.

Risyad Harun, M. (2003) Partisipasi Masyarakat Terhadap Pelayanan Posyandu di Puskesmas A.yani. Skripsi Fakultas Kedokteran Universitas Kristen Maranatha.

Setiadi. (2007). Konsep dan Penulisan Riset Keperawatan. Yogyakarta : Graha Ilmu.
Rahmawarni, Sri (2008). Hubungan Motivasi Berprestasi Dengan Pencapaian Prestasi Kerja Karyawan PT.Indogruve. Skripsi. UIN Syarif Hidayatullah, Jakarta.

Syafrudin, dkk. (2009). Ilmu Kesehatan Masyarakat Untuk Mahasiswa kebidanan. Trans Info Media. Jakarta.

Miftah, Toha. (2011). Perilaku Organisasi Konsep Dasar dan Aplikasinya, Jakarta : PT Fajar Garfindo Persada 